\title{
HOW TO INCORPORATE CAD/CAM FABRICATION INTO A BASIC DESIGN STUDIO? A PRELIMINARY FRAMEWORK FOR THE "E-BASIC DESIGN STUDIO"
}

\section{COMO INCORPORAR A FABRICAÇÃO CAD/CAM EM UM ATELIER DE PROJETO BÁSICO? UMA ESTRUTURA PRELIMINAR PARA O "E-BASIC DESIGN STUDIO"}

\author{
Chor-Kheng Lim \\ Assistant Professor, Yuan Ze University, Department of Art and Design, kheng@ saturn.yzu.edu.tw
}

\begin{abstract}
The objective of this study is to apply the teachings of CAD/CAM fabrication to basic design studios for 1st and 2nd year undergraduate students. Consequently, the study concludes with an "e-basic design studio" framework based on literature analysis and design studio observations, which includes new tectonics thinking and the operation of traditional 2D/3D design tools and $\mathrm{CAD} / \mathrm{CAM}$ digital tools.
\end{abstract}

Keywords: Design education; Basic Design Studio; CAD/CAM design tool; digital thinking.

\section{Introduction}

In the theory of design thinking, Schön (1992) proposes that design behavior is the process of conversation between designers and their media. With the aid of various design media, designers present design ideas that are in their minds. Utilizing a variety of media influences the process of design thinking because of different operation and presentation methods (Zevi, 1981; Liu, 1996; Bilda \& Demirkan, 2003; Lim, 2003, 2006). The media can play an important role in the design process, and the use of different media can cause limitations in the design process. Therefore, in different periods, there are different media developments with different presentation methods. Prior to the Renaissance period, architects presented design ideas by drawing twodimensional (2D) plans, elevations, and sections. Designers in the Renaissance period gradually felt that 2D drawings could no longer suitably present complex forms confined in the minds of designers. Hence, Fillipo Brunelleschi started to use three-dimensional (3D) thinking as an auxiliary design (Million, 1994) that led to large quantities of 2D drawings and 3D physical models in design process, which shortened the gap between conceptual design and built work (Liu, 1996; Smith, 2004). The making process of 3D physical models allows designers to clearly experience the relationships between the outer and inner building structures.

Contemporary design processes utilize large amounts of application of traditional design media such as 2D hand- drawn sketches, plans, elevations, sections, perspectives, and 3D handcrafted physical models. Since 2000, digital design media such as 2D or 3D computer-aided design (CAD) and new digital media such as computer-aided design/computer-aided manufacture (CAD/CAM) have increased in popularity and expanded new possibilities within architectural design frameworks. These new CAD/CAM design media subvert building technologies, fabrication, and forms with complex components, all of which cannot be fulfilled with traditional media (Kolarevic, 2001). The application of new CAD/CAM digital media has become an important trend in the 21st century "digital age," influencing everything from architectural practice to architectural education. The CAD/CAM digital construction process has expanded the potential applications of computer-aided design (CAD), which used to be employed only as tool for visualizing the creation or simulation of complex design forms. Digital control technologies such as laser cutting, computer numerical control (CNC), and rapid prototyping (RP) have been utilized to fabricate free and complex CAD design forms (Kolarevic, 2003; Schodek et al., 2005; Sass, 2006; Lim, 2009), making the impact of digital technology to architectural forms undeniable (Lynn \& Rashid, 2002). Moreover, new CAD/CAM digital media have changed traditional design methods and design thinking and have already become an important design medium in contemporary design processes. 
Ever since digital tools were developed and applied to the architectural field in 1980s, researchers have actively discussed how to incorporate digital design instruction into traditional architectural education (Andia, 2001). The evolution of digital design education started thirty years ago and included all sorts of applications as shown in Figure 1, such as computer-aided design, computersupported design, computer-generated design, and computer-augmented design. With these constantly changing digital tools, various characteristics of design studios in architecture education were developed. The initial development of electronic design studio courses (Mitchell \& McCullough, 1991), virtual design studio courses, and collaborative design studio courses gave way to digital design studio courses, which have been actively developed by schools in recent years (Chiu, 2003). Given that there are close relationships between the development of design studio courses and the needs of architectural practitioners and that CAD/CAM technology greatly influences the development and research of international architecture, this study focuses on the relationships between CAD/CAM digital media and the development of design studio courses.

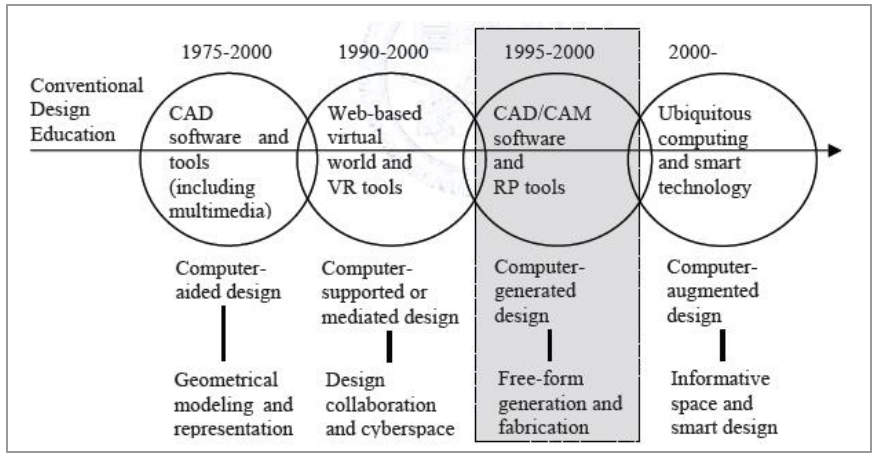

Figure1. Evolution of digital design education (after Chiu, 2003)

Since 2000, researchers have been discussing how to apply digital tools to architectural education, specifically how to include CAD/CAM tools into the content of design studios and courses. Institutions such as MIT, Harvard, Columbia, Architectural Association School of Architecture (AA), and the Swiss Federal Institute of Technology Zurich (ETH) have been among those leading these efforts (Campbell, 2006; Garber and Jabi, 2006; Kalay, 2006; Schoch, 2006). Meanwhile, many researchers have started to discuss the impact of $\mathrm{CAD} / \mathrm{CAM}$ tools used in the design courses and have offered suggestions for architectural design teaching courses (Ceccato, 2004; Jabi, 2004). Through hands-on use of CAD/CAM tools in design studios, CAD/CAM case studies, and experimental studies of CAD/CAM courses, researchers have proposed educational frameworks incorporating CAD/CAM design and manufacturing processes (Boza, 2006; Larsen, et al., 2008). In addition, Barrow (2006) and Iordanova (2007) indicate that design studios utilizing $\mathrm{CAD} / \mathrm{CAM}$ tools must employ two stages of teaching: basic skill training courses and advanced digital design creation. Researchers also discuss how to incorporate professional systems, such as Gehry Technologies or Generative Components (GC), into the teaching framework of digital design studios (Hanna \& Turner, 2006; Mark, 2008).

Previous research indicates that current CAD/CAM technology has become an important design medium to design and manufacturing processes. Moreover, the incorporation of CAD/CAM technology to studio teaching frameworks is a major development in architectural education and research fields, both domestically and internationally. However, these CAD/CAM courses were usually planned for advanced design students (4th-5th year undergraduate and graduate students) due to their highly technical content. In recent years, however, these tools have become increasingly popular in the architectural design process and education programs, and some researchers have begun to study how to apply digital tools to basic design studios (Shih, 1996; Chien, 2007). In 1996, Naai-Jung Shih was already discussing how to use CAD in basic design studios and offered suggestions for CABD (computer-aided basic design) studios (Shih, 1996). Through case studies and teaching experiments, Sheng-Fen Chien et al. (2007) planned a series of applied CAD digital-aided design studios for various skill levels. These researchers apply CAD to basic design studios, extend the application of CAD beyond presentation uses, and allow novices to start the application of 3D digital modeling.

\section{Emergent digital design studios}

The prices of CAD/CAM equipment such as laser-cutting machines and rapid prototyping machines tend to be more affordable than ever before. Moreover, changes in design media will influence design thinking and design processes. If $\mathrm{CAD} / \mathrm{CAM}$ fabrication teaching methods can be properly adjusted and simplified to allow novices in basic design studio courses to use emerging media, then these students will possess a more diversified skill set than those exposed to traditional, basic design training. Furthermore, researchers have studied teaching courses using various media on an experimental basis and discussed the role of CAD/CAM digital media in the design process and in generating digital tectonic thinking (Jabi, 2004; McLachlan et al., 2007; Petrovic, et al., 2007; Wallick, 2007; Liu \& Lim, 2009). Chiu \& Lou (2006) posit that the application of CAD/CAM media to design studio teaching has not only been a training tool, but it has also inspired students to generate new tectonic thinking. 
It can be learned from this that, with the evolution of the era, the incorporation of digital media in the planning of design studio courses has been critical and important for novice designers to learn the application of CAD/CAM digital media and to be trained with digital design thinking. To train designers with the application of new design media and new tectonic thinking, this study discusses how to start teaching the application of CAD/CAM digital tools (i.e., parametric design CAD software and CAM hardware such as laser cutter, rapid prototyping, CNC milling machines, and 3D scanners) in basic design studio courses. Furthermore, it attempts to discover teaching methods that can lower the educational threshold for CAD/CAM digital media through combining traditional design media with digital design media and equip design novices with traditional and digital design thinking. Therefore, the purposes of this study are as follows:

1.To include $\mathrm{CAD} / \mathrm{CAM}$ fabrication teaching in basic design studio courses, observe the proficiency with which design novices use digital media, and propose several new methods, which influence the design thinking of novices who use CAD/CAM digital media.

2.To utilize empirical research in the development of a preliminary "e-basic design studio" teaching framework comprised of mutual applications and new tectonic thinking between traditional 2D/3D design media and $\mathrm{CAD} / \mathrm{CAM}$ digital media.

\section{Methodology and steps}

This study comes in two parts: 1 . a literature review and 2. participant observations on how to develop a teaching framework for an "e-basic design studio".

Step 1: Literature review

In the first step, we integrated "teaching purposes," "the training of media operations" and "design thinking" into the traditional basic design studio format from collected research data. This included literature analysis and case observations from basic design courses. Then, we integrated digital tool operation and digital tectonics thinking based on the research of Iwamoto (2009) and Liu and Lim (2006). Based on these analyses, we defined "the training of media operations" and "design thinking" in both the traditional and digital design studios to establish a preliminary framework for the "e-basic design studio."

\section{Step 2: Participant observations}

As the purpose of this study is to propose a teaching framework for a basic design studio, it applies the preliminary teaching framework of the "e-basic design studio" to a real course (the 2 nd year undergraduate basic design studio at the Department of Art and Design, YuanZe University) for two design projects. Using participant observations, we obtained the data we needed for analysis. From the studio observations in the first design project, we determined the teaching effectiveness and noted some aspects of design in the students' design outcomes. The teaching framework was modified according to the analysis and applied again in the second design project to validate its feasibility. Finally, we integrated an executable preliminary teaching framework for an "e-basic design studio" for design novices, which included new tectonics thinking and the operation of traditional 2D/3D design tools (2D drawing, 3D modeling) and CAD/CAM digital tools.

\section{A preliminary framework for the "e-basic design studio"}

\section{Traditional basic design studio}

\section{"Teaching purposes"}

The current design education, which offers fundamental "basic design studios" to novice students, originates from a design education model developed by the Bauhaus and its founder, Walter Gropius. At that time, six-month "elementary courses" were offered. They integrated art, architecture, crafts, science and other topics to offer basic knowledge, techniques, and concepts. They included "fundamental studies on form," "fundamental studies on materials," and "studies on composition" (Wang, 2003). The teaching goal in these courses focused on concept and operation, the development of students' creative thinking and all types of early stage professional training (Ni, 2009). Due to the tendency of basic design studios today to both continue and value the teachings of the Bauhaus, this research will define the teaching purposes of traditional (non-digital) basic design studios with the following three points:

\section{Design concepts and operation training.}

\section{Development of creative potentiality.}

\section{Early stage professional design training.}

\section{"The training of media operations"}

The design media used in traditional basic design studios are mainly sketches, handcrafted models, and photography. The tools for sketches include pencil, watercolor, charcoal among others. More materials are used in model making. Major materials, which are generalized by Naomi Asakura (1992) when discussing the materials used in 3D composition, include paperboard, clay, wood, metal, plastic, and ceramics. 
Schools in Taiwan tend to use styrofoam and cardboard, both of which are easily cut, and resin, which is easily shaped. To train students to apply various materials to the making of models, especially wood and metal for which special equipment is needed or specific technologies are required, many design departments set up woodwork and metalwork shops to offer hands-on experience and teaching. In addition, in traditional basic design education students often present their design ideas through photography or pictures. As the students are still not trained in digital drawing, their photographic works are the easiest and most direct way for presenting their concepts. Hence, this study reduces the media application training of traditional (non-digital) basic design studios into the following three methods:

1. Sketch: drawn with pencil, watercolor, or charcoal.

2. Handcrafted model: models made with materials such as cardboard, clay, wood, metal, plastic, ceramics, styrofoam, and resin.

3. Photography: an easy way to present, select and cut tableaus, and present design ideas.

\section{"Design thinking"}

Shun-Chen Ni (2009) integrates several important operational practices in his research on traditional basic design studios, including simplification, 2D composition, 3D composition, and material studies. These practices, which are basic knowledge, skills and the concepts of "form," "materials" and "composition" are all based on the concept of basic education developed by the Bauhaus. In these operational processes, "form"-based design training aims to transform abstract conceptual thinking into simple 2D compositions, and then further transform it into 3D compositional models. Especially for operational practices in departments like architecture and industrial design, 2D concepts will be first developed into $2.5 \mathrm{D}$, and finally transformed into a 3D format. For example, the most common design topic in architecture basic design studios is "the transformation of 2D graphics into 3D models." For media used in design presentations, students are trained to know and study characteristics of different materials. It is therefore necessary to include the selection and understanding of materials in design thinking. Meanwhile, in design presentations, regardless of the representational tool, students are trained to creatively compose different graphics or materials based on the basic elements of composition: points, lines, planes, solids, and spaces. In the process of composition, especially in 3D composition, the construction methods of materials and structural relationships are taken into consideration. "Operation and regeneration of objects" is a common design topic in architecture design studios and trains students to magnify small, daily objects and recompose them according to their own interpretation of composition and construction methods. Therefore, this study reduces the training of design thinking in traditional (non-digital) basic design studios into the following five elements:

1. Form: abstract concepts $\rightarrow 2 \mathrm{D}$ sketches $\rightarrow 2.5 \mathrm{D}$ models $\rightarrow$ 3D models.

2. Materials: thinking about the characteristics of materials and how to apply them.

3. Composition: thinking about different graphic and material compositions based on compositional elements, including points, lines, planes, solids, and spaces.

4. Structure: thinking about the structure of form and materials in 3D composition.

5. Construction: thinking about the construction of different materials in 3D composition.

\section{Digital basic design studio}

\section{"Teaching purposes"}

This study attempts to train design novices who are not proficient in the digital design process. Given this, it is essential to teach students how to operate the digital tools used in a basic design studio. At the same time, design novices are trained to become familiar with integrating traditional and digital design media into their design processes. The digital basic design studio will extend the teaching purposes of traditional (i.e., non-digital) basic design studios, as it will incorporate the digital tool training associated with computer courses and workshops. It has the following two teaching purposes:

\section{Digital design concepts and operation training.}

\section{Integrating traditional and digital design media.}

\section{"Digital tools operation"}

In the digital design process, many software and hardware tools are used as design media. They include 2D image processing software (e.g., Photoshop, Illustrator). CAD software (e.g., AutoCAD, SketchUp, 3dMax, Rhino, Maya, CATIA), and CAM machines (e.g., laser cutter, Rapid prototyping (RP), CNC, 3D scanner). The operations of these CAD/CAM design tools enable the production of $2 \mathrm{D} / 3 \mathrm{D}$ drawings and $3 \mathrm{D}$ physical models. In the past, CAD tools were only used to represent $2 \mathrm{D}$ drawings and $3 \mathrm{D}$ modeling. Today, however, the application of CAD/CAM tools enables the 
precise fabrication of physical models from complicated 3D model data. This digitized model-making process is called digital fabrication. The process of digital fabrication begins by building a 3D design form using CAD software with different modeling methods, such as surface control point editing or parametric design. Then, the $3 \mathrm{D}$ model is converted into a readable file for the CAM machine. Finally, the physical design components or model is fabricated by the CAM machine. This operation is different from traditional model-making methods, leading Iwamoto (2009) to define five types of digital fabrication techniques: sectioning, tessellating, folding, contouring, and forming. At present, these operations are taught in advanced computer courses at many schools. The aim of this study is to train design novices in the basic operations of digital CAD/CAM tools. Hence, this study concludes the media application training of digital basic design studios into the following three methods:

\section{Digital 2D drawings:}

a. 2D image editing: using software such as Photoshop and Illustrator.

b. 2D plan, elevation drawing: using CAD software such as AutoCAD.

\section{Digital 3D models:}

a. Using surface control point editing as a modeling method: CAD software such as AutoCAD 3D, SketchUp, 3dMax, Rhino, Maya, and CATIA.

b. Using parametric as a modeling method: CAD software such as Rhino, Grasshopper, Maya MEL, and $3 \mathrm{ds}$ Max scripts. This operation enables the building of complicated freeform models.

\section{3D CAM physical models:}

a. Laser-cut model: Decompose 3D model to 2D components, transfer the 2D data file to the laser cutter machine for cutting and then assemble the cut components to form a 3D physical model. The materials used include cardboard, acrylic, wood, and others; the fabrication techniques include sectioning, tessellating and folding.

b. RP model: Export 3D model to an iges file and send to the RP machine, and then physical models are precisely fabricated layer by layer. The materials used include ABS, resin, and others; the fabrication techniques include tessellating.

c. CNC model: Fabricate the physical model by subtracting the material. Common materials for this technique include wood blocks, acrylic, ABS, PU foam, aluminum, and others; the fabrication techniques include contouring and forming. d. 3D scanned model: Physical model is scanned to become a point cloud, and then exported to a 3D model.

\section{"Digital tectonics thinking"}

The use of different design media will change design thinking in the design process (Lim, 2003). Lim (2003) conducted protocol analysis to compare the design thinking of using hand-drawn sketches and digital penbased sketches, and consequently concluded that digital pen-based sketches elicited more visual feedback to affect designers' design thinking. Some researchers also compared the design thinking using in traditional handcraft modeling and digital 3D modeling. They point out that 3D models are easy to modify, especially via the "zooming" operation, which aided in achieving design detail and scale control. However, 3D models lack physical characteristics. Hence, CAD/CAM fabrication is becoming more popular, as it creates a physical model using 3D model data. Meanwhile, the evolution of modeling methods from intuitively control point editing to mutative parametric modeling provides us with the liberty of form generation. To explore the tectonic thinking of using CAD/CAM tools in the design process, Liu and Lim (2006) analyzed 15 digital design cases and integrated a preliminary framework of new tectonics involving classic and digital thinking. This framework includes seven traditional tectonics factors: joint, detail, material, structure, construction, and four digital tectonic factors of animation, generation, information, and fabrication. Furthermore, in order to better understand how CAD/CAM tools can aid design thinking, Lim (2006) conducted cognitive experiments to conclude the following:

Laser cutter : The fabrication of the physical model is based on a $2 \mathrm{D}$ cutting process. A complicated or freeform 3D CAD model is decomposed to its 2D skin and structural elements, which can then be fabricated using a laser cutter. Following this, the cut, physical elements are assembled into a complete model. This method facilitates the consideration of structure and better follows actual construction methods.

Rapid prototyping : The fabrication of physical models is based on the 3D manufacturing process. A complicated or free form 3D CAD model is transformed directly into a complete 3D physical model, layer by layer. Designers need not worry about the difficulty of making complicated forms, and this process facilitates the consideration of designed form. 
Design thinking using digital tools is different from the traditional design process based on the results of the research mentioned earlier. Especially in digital form generation aided by CAD operations, model fabrication aided by the CAM machine, and the accuracy afforded by the digital tools enable designers to consider detail, dimension and scale. Therefore, this study concludes that design thinking training of digital basic design studios can be encapsulated by the following three items:

\section{Digital form:}

a. Abstract concepts $\rightarrow$ point editing control $\rightarrow 3 \mathrm{D}$ digital model $\rightarrow$ 3D CAM physical model (RP).

b. Abstract concepts $\rightarrow$ parametric setting $\rightarrow 3 \mathrm{D}$ digital model $\rightarrow$ 3D CAM physical model (RP).

\section{Digital tectonics:}

a. (Laser cutter) 3D digital model $\rightarrow 2 \mathrm{D}$ dismantling $\rightarrow 3 \mathrm{D}$ assembly. It is able to facilitate the design thinking of material, structure and construction.

b. (Rapid prototyping \& CNC) 3D digital model $\rightarrow$ 3D CAM physical model. It is able to facilitate the design thinking of form.

\section{Digital accuracy:}

The "zooming" operation in CAD modeling can aid the design thinking of detail. The output of the CAM physical model aids in the design thinking of scale.

\section{A preliminary framework for the "e-basic design studio"}

Based on the previous analysis of traditional and digital basic design studios, this study proposes a four-module teaching framework utilizing four design stages: conceptual, preliminary, detailed, and manufactured. In the early stages, especially in conceptual and preliminary design, we apply the training of using traditional design media. In addition, we incorporate digital CAD/CAM media into the model making process, which is in detailed, and manufacture modules. A preliminary framework for the "e-basic design studio," which integrates the use of traditional 2D/3D design media and digital CAD/CAM tools, is shown in Figure 2.

\section{Participant observations}

The "e-basic design studio" framework was applied to a real design studio (second year undergraduate) at the Department of Art and Design, YuanZe University, which had 17 students in the studio. Using participant observations, we obtained the data from two different design projects during the semester (18 weeks). We determined the teaching effectiveness and noted some aspects of design in the students' design outcomes. The teaching framework was modified according to the analysis and applied again in the second design project to validate its feasibility. From this study, we chose five students' works for analysis according to the evaluation of the teacher. The following describes the design process and results:

\section{Design Project 1 : Deformable furniture design}

1. Aim: To train students to transform 2D graphics into a 3D thought process and at the same time, teach the integration of traditional design media and digital CAD/CAM tools (i.e., laser cutter).

2. Design topic: Find a pattern in nature, develop three kinds of continuous 2D patterns, and then transform them into a 3D design of deformable multi-functional furniture. Complete the design in a 1:1 scale physical model using acrylic and wood materials.

3. Design media: Traditional design media (i.e., sketch, handcrafted paper model); and digital CAD/CAM tools (i.e., AutoCAD 2D, laser cutter).

\section{Design outcomes:}

\section{Module1 (1 week): Conceptual design}

Figure 3 shows the designs presented with hand drawings, photographs, and Photoshop drawings.

\section{Module2 (4 weeks): Preliminary design}

Figure 4 shows the designs presented with hand drawings and handcrafted models $(2.5 \mathrm{D} \rightarrow 3 \mathrm{D}$ model $)$.

\section{Module3 (2 weeks): Detail design}

Figure 5 shows the designs presented with CAD drawings and handcrafted models.

\section{Module4 (2 week): Manufacture}

Figure 6 shows the manufacturing process. The students used laser cutter to cut the design components that were assembled in the woodwork shop. Figure 7 shows the final 1:1 acrylic, deformable, multifunctional furniture design.

\section{Summary:}

From the design outcomes, we learned that the students' thinking starts with $2 \mathrm{D}$ and switches to $3 \mathrm{D}$ using drawings and model representations. Some students used digital tools (Photoshop) in Module 1 to develop (i.e., copy, rotate, scale) the patterns. As they 
were just started being trained in using CAD/CAM tools, the students still used many handcrafted models in Module 3 instead of making CAM models. Based on these findings, the framework was modified as follows:
Modification 1: Add "digital 2D drawing" in Module 1.

Modification 2: Add "3D CAM physical model" in Module 2 to teach the use of CAD/CAM tools earlier.

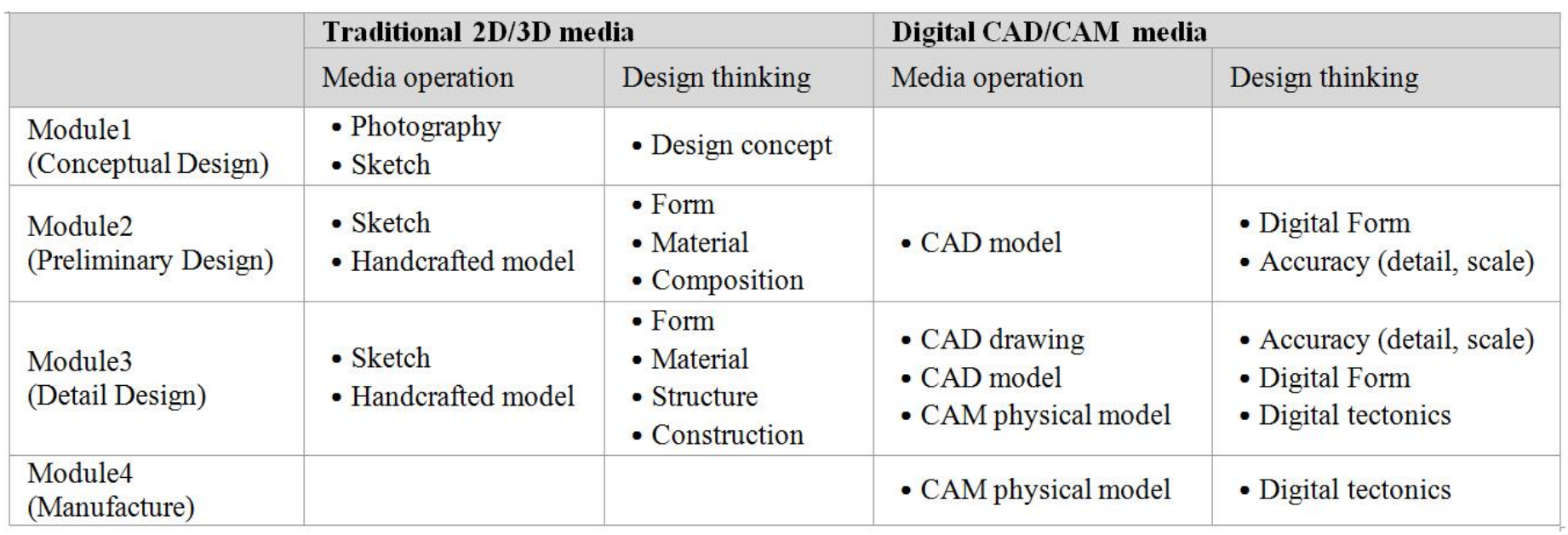

Figure2 A preliminary teaching framework for the "e-basic design studio"
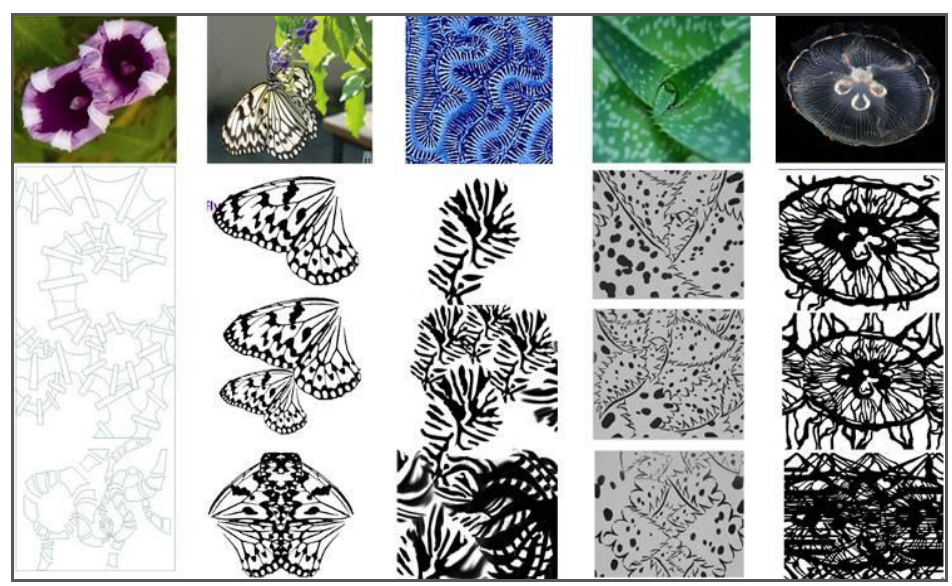

Figure 3 Conceptual design
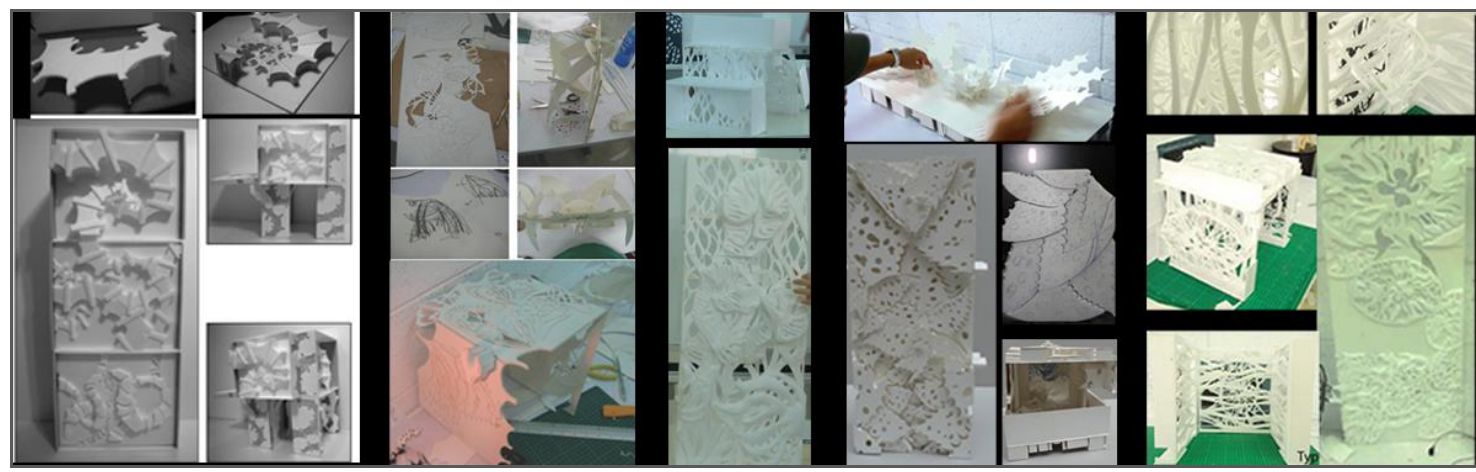

Figure 4 Preliminary design 


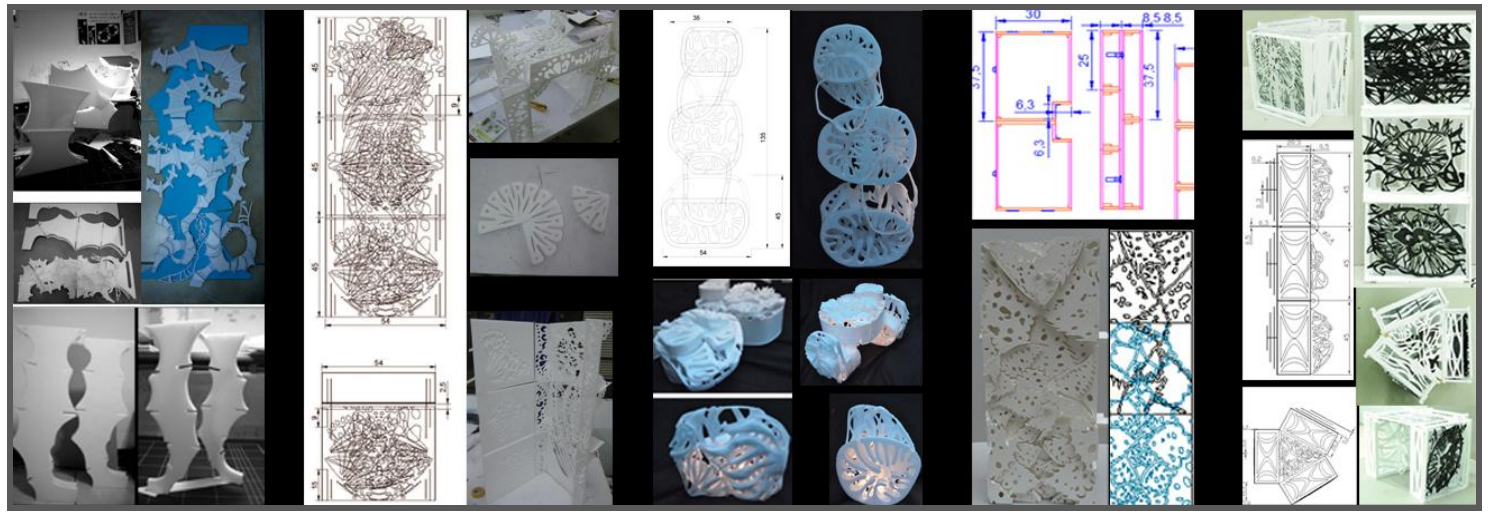

Figure 5 Detail design

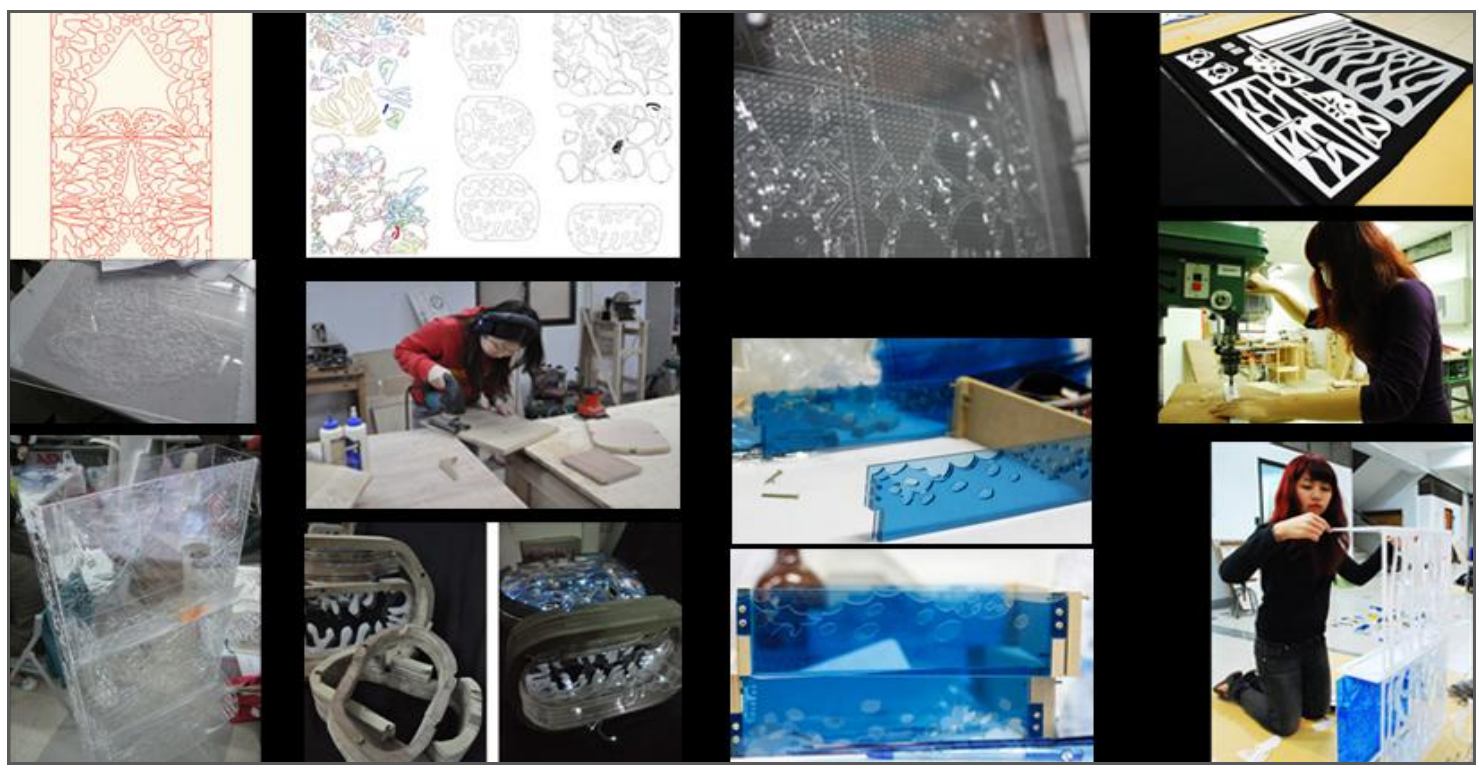

Figure 6 Manufacture

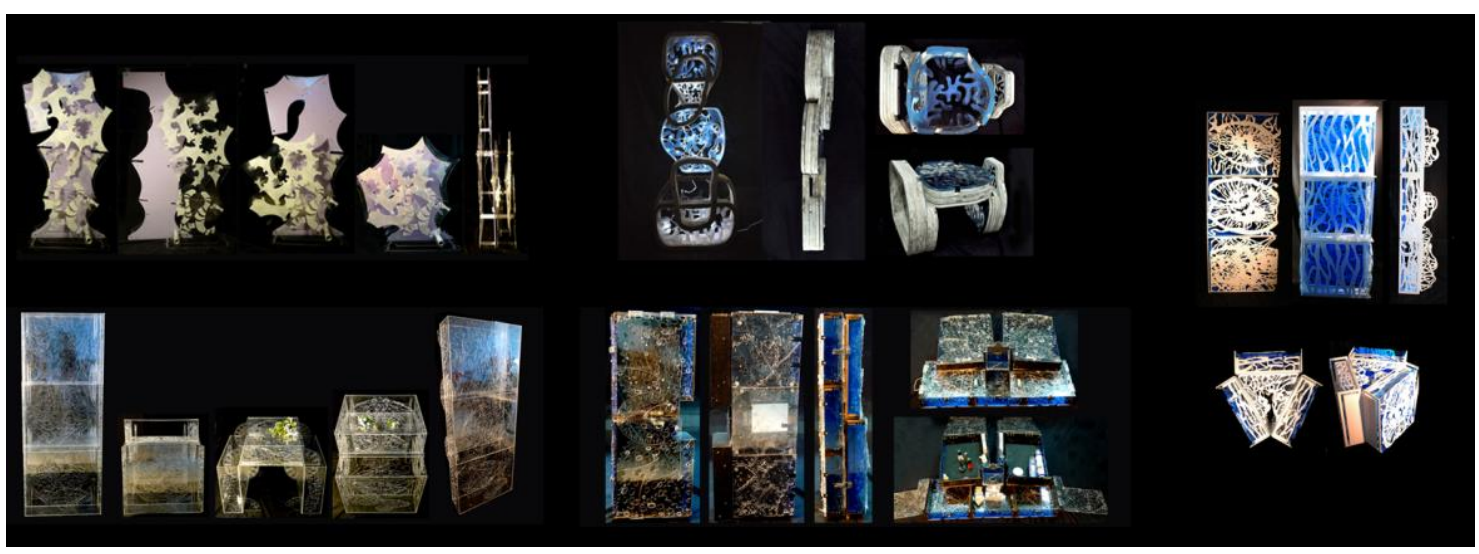

Figure 7 Final design

\section{Design Project 2 : Personal reading space design}

1. Aim: To train students to interpret 1D text (Literature) and develop it into 3D spatial design. To familiarize themselves with their body and spatial relationships and to consider structural design thinking while teaching them how to integrate traditional design media with digital CAD/CAM tools (i.e., styrofoam cutter).

2. Design topic: Interpret 1D text (i.e., description of the space) into 3D spatial design through reading short essays. Develop 3D personal reading space based on body posture and text strokes. Complete the design in a 1:1 physical model using styrofoam materials. 
3. Design media: Traditional design media (i.e., sketch, handcrafted styrofoam model) and digital CAD/CAM tools (i.e., AutoCAD 3D, styrofoam cutter)

\section{Design outcomes:}

\section{Module1 (1 week): Conceptual design}

Figure 8 shows the designs presented by hand drawings, photographs, Photoshop drawings and CAD dimensional drawings.

Module2 (3 weeks): Preliminary design

Figure 9 shows the designs presented by CAD drawings, handcrafted models, 3D models, and physical CAM study models (i.e., styrofoam cutter).

Module3 (2 weeks): Detail design

Figure 10 shows the designs presented by 3D simulations, 3D models (i.e., sectional model) and CAD drawings (i.e., components and units).

Module4 (3 weeks): Manufacture

Figure 11 shows the manufacturing process. The students used the styrofoam cutter to cut design components and then assemble them. Figure 12 shows the final 1:1 styrofoam personal reading space design.

\section{Summary:}

The design outcomes show that the students' thinking starts with 1D text and transforms to 3D shapes through the use of drawings and model representations. In this project, the students are more familiar with CAD/CAM tools; they fabricated their CAM study models in Module 2 with the aid of a styrofoam cutter. As their designs can be easily modified in the 3D models, they rely on digital tools in Module 3 to prepare the drawings for fabrication. They consider the detailed design intuitively when using CAD/CAM tools. Because of this, the framework was modified again as follows:

Modification 3: The use of traditional design media in Module 3 is optional.

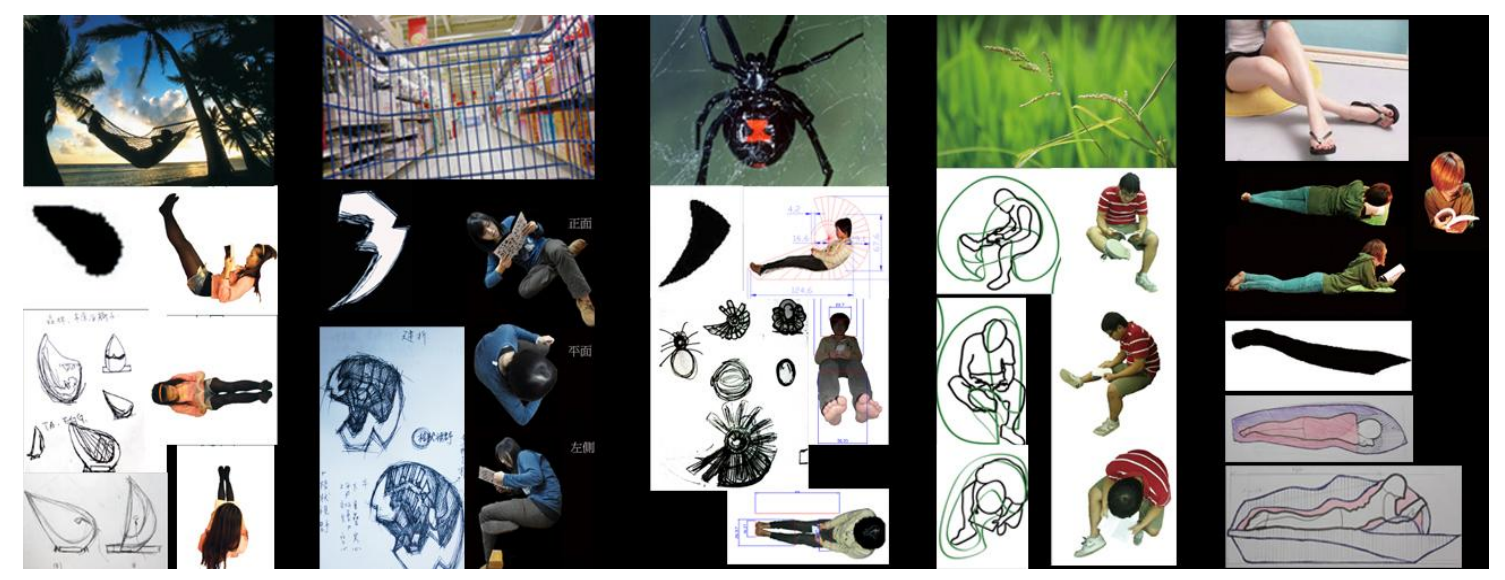

Figure 8 Conceptual design
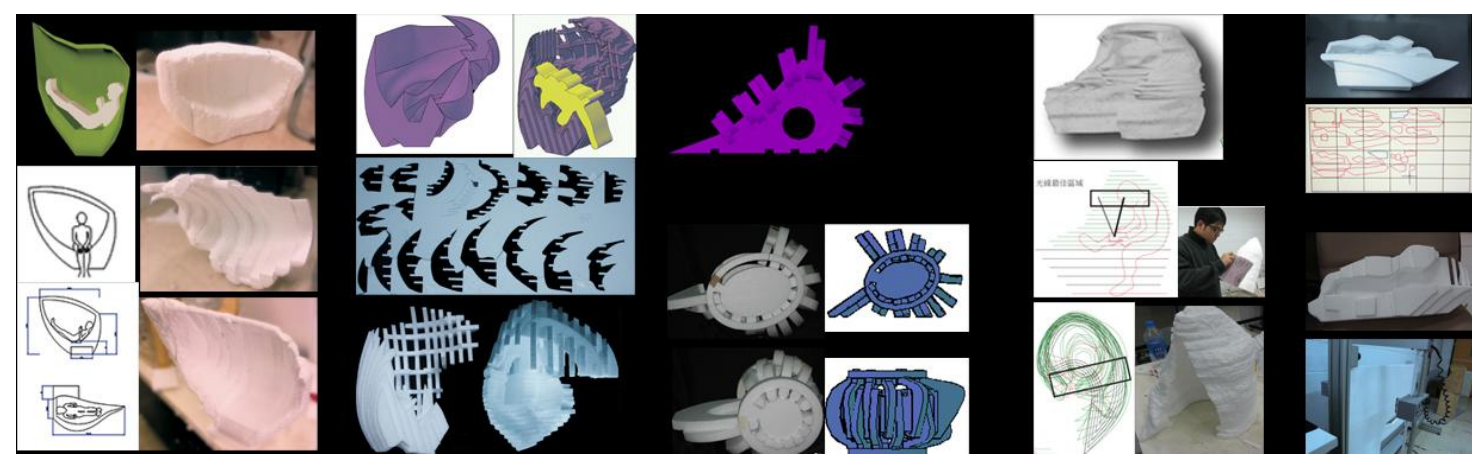
Figure 9 Preliminary design

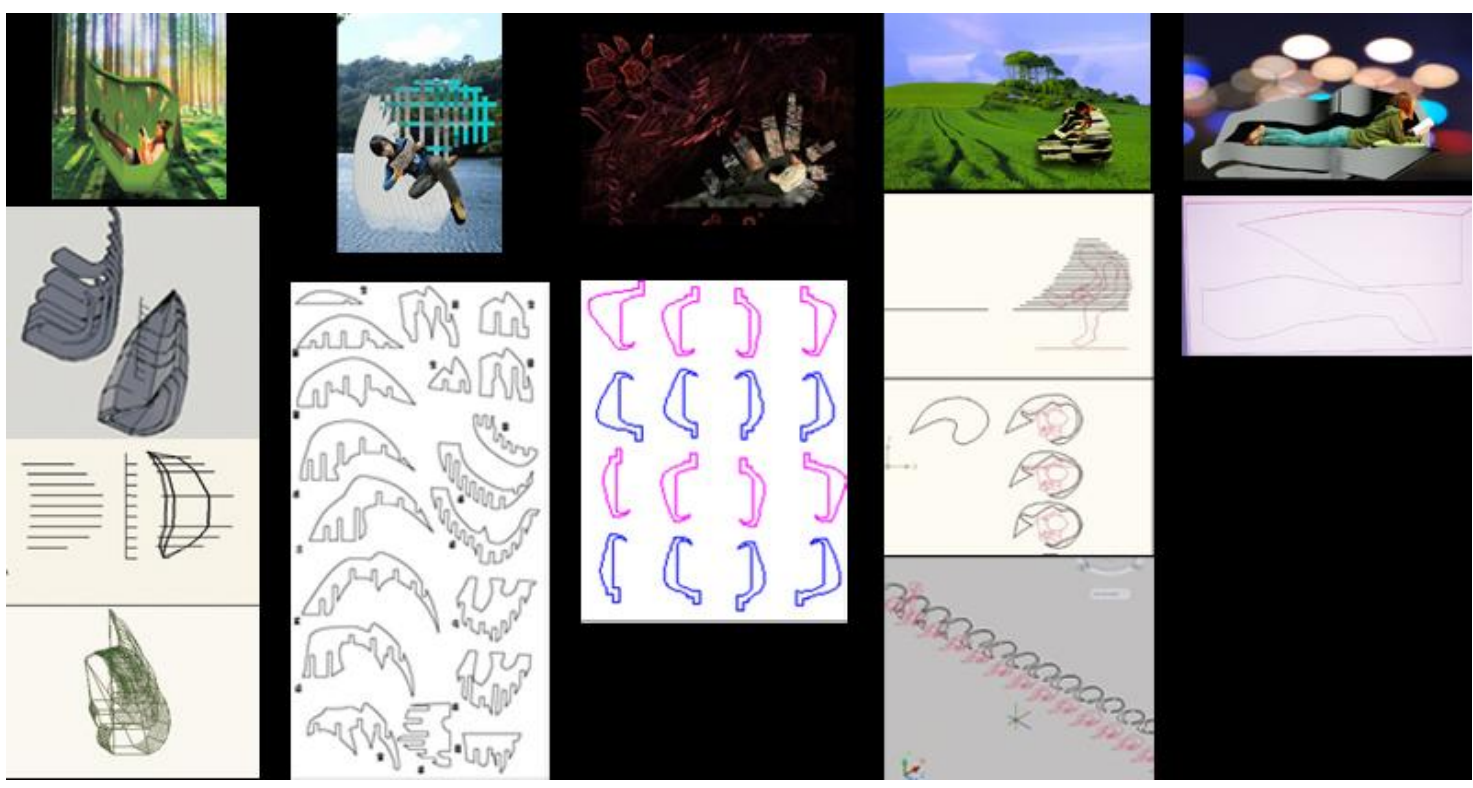

Figure 10 Detail design

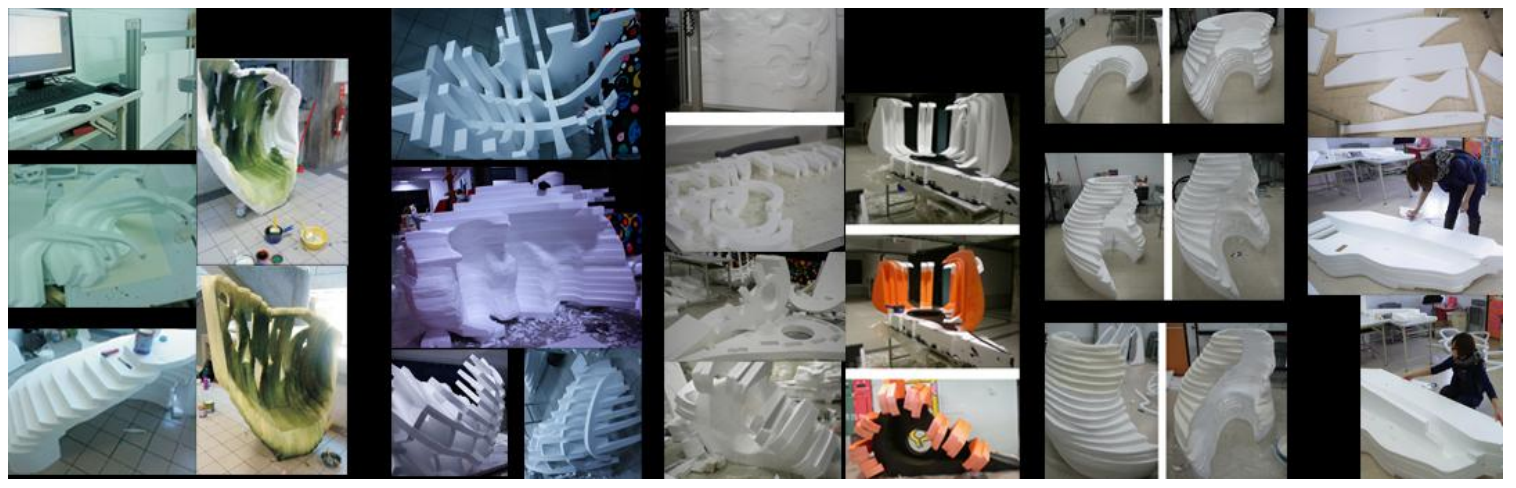

Figure 11 Manufacture

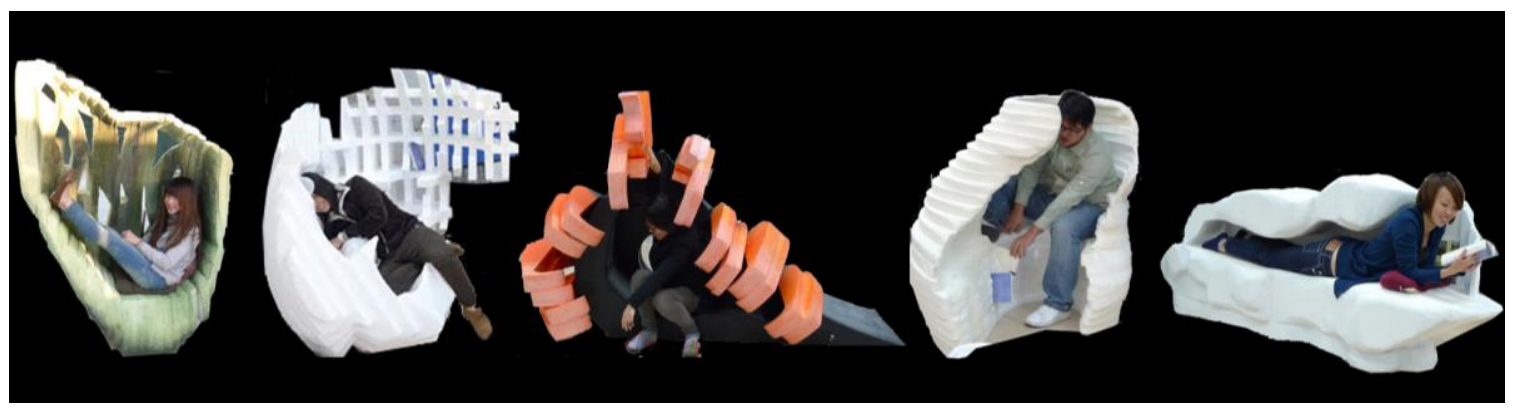

Figure 12 Final design

\section{Results}

From the analysis of design outcomes, it is clear that after applying the "e-basic design studio" teaching in the two design projects, the students, all design novices, were well familiarized with the implementation of both traditional 2D/3D and digital CAD/CAM media in their design projects.
This study produced an executable teaching framework suitable for the "e-basic design studio" (Figure 13). We propose a new teaching method for novices in the design studio that integrates both traditional design media and digital CAD/CAM tools in the design process. In addition, this study draws some conclusions regarding the design outcomes and processes for the "e-basic design studio": 
1. Design novices are more focused on their design concept development when using traditional media but more attentive to the scale, material, structure and construction procedure when using CAD/CAM tools.

2. Design novices are able to think about the construction procedure during the assembly process.

3. Design novices are more focus on design detail while using CAD/CAM tools in the early design stage.
4. Design novices become more familiar with the conversion of $2 \mathrm{D} / 3 \mathrm{D}$ design thinking in the process of integrating traditional and digital tools.

5. Design outcomes can be more precise at any scale of the model and can even produce works at a scale of $1: 1$.

\begin{tabular}{|c|c|c|c|c|}
\hline & \multicolumn{2}{|c|}{ Traditional 2D/3D media } & \multicolumn{2}{|l|}{ Digital CAD/CAM media } \\
\hline & Media operation & Design thinking & Media operation & Design thinking \\
\hline $\begin{array}{l}\text { Module1 } \\
\text { (Conceptual Design) }\end{array}$ & $\begin{array}{l}\text { - Photography } \\
\text { - Sketch }\end{array}$ & - Design concept & - 2D drawing (image) & - Design concept \\
\hline $\begin{array}{l}\text { Module2 } \\
\text { (Preliminary Design) }\end{array}$ & $\begin{array}{l}\text { - Sketch } \\
\text { - Handcrafted model }\end{array}$ & $\begin{array}{l}\text { - Form } \\
\text { - Material } \\
\text { - Composition }\end{array}$ & $\begin{array}{l}\text { - CAD model } \\
\text { - CAM physical model }\end{array}$ & $\begin{array}{l}\text { - Digital Form } \\
\text { - Accuracy (detail, scale) }\end{array}$ \\
\hline $\begin{array}{l}\text { Module3 } \\
\text { (Detail Design) }\end{array}$ & $\begin{array}{l}\text { (*optional) } \\
\text { - Sketch } \\
\text { - Handcrafted model }\end{array}$ & $\begin{array}{l}\text { (*optional) } \\
\text { - Form } \\
\text { - Material } \\
\text { - Structure } \\
\text { - Construction }\end{array}$ & $\begin{array}{l}\text { - CAD drawing } \\
\text { - CAD model } \\
\text { - CAM physical model }\end{array}$ & $\begin{array}{l}\text { - Accuracy (detail, scale) } \\
\text { - Digital Form } \\
\text { - Digital tectonics } \\
\text { (material, structure, construction) }\end{array}$ \\
\hline $\begin{array}{l}\text { Module4 } \\
\text { (Manufacture) }\end{array}$ & & & - CAM physical model & $\begin{array}{l}\text { - Digital tectonics } \\
\text { (material, structure, construction) }\end{array}$ \\
\hline
\end{tabular}

Figure 13 A modified preliminary teaching framework of the "e-basic design studio".

\section{References}

Andia, A. (2001). Integrating digital design and architecture during the past three decades. In Proceedings of the 7th International Conference on virtual systems and multimedia. Berkeley, CA:Virtual systems and multimedia, 677 - 686.

Asakura, N. (1992). Fundamental problems of creating in the three-dimensional space. Taipei: Basic Art \& Design Series.

Barrow, L.R. (2006). Digital design and making 30 Years after. In Proceedings of the 25th Annual Conference of the Association for Computer-Aided Design in Architecture (ACADIA). 158-177.

Bilda, Z., \& Demirkan, H. (2003). An insight on designers' sketching activities in traditional versus digital media, Design Studies 24, 27-50.

Boza, L.E. (2006). (Un)Intended Discoveries: Crafting the Design Process. In Proceedings of the 25th Annual Conference of the Association for Computer-Aided Design in Architecture (ACADIA). 150-157.

Campbell, C. (2006). Digital design pedagogy setting the foundation for digital design in the srchitecture curriculum. In Proceedings of the Conference of the Association for Computer-Aided Design in Architecture (ACADIA). 411-417.

Ceccato, C. (2004). Evolving tools: Digital fabrication in architectural education. In Proceedings of the Association for ComputerAided Design in Architecture (ACADIA).

Chien, S.F., Tseng, H.M., \& Shih, S.K. (2007). Fundamental trainings of designers of digital architecture. Taiwan National Science Council Project 96-2516-S-006-004-

Garber, R., \& Jabi, W. (2006). Control and collaboration: digital fabrication strategies in academia and practice. International Journal of Architectural Computing 4(2), 121-143.

Hanna, S., \& Turner, A. (2006). Teaching parametric design in code and construction. In Proceedings of the 10th SIGraDi, Santiago de Chile, Chile, 158-161.

Iordanova, I. (2007). Teaching digital design exploration: Form follows. International Journal of Architectural Computing 5, 685702.

Iwamoto, L. (2009). Digital Fabrications: Architectural and material techniques. New York: Princeton Architectural Press.

Jabi, W. (2004). Digital tectonics: The intersection of the physical and the virtual. In proceedings of the ACADIA Conference, Fabrication: Examining the Digital Practice of Architecture, Cambridge, Ontario. 256-269.

Kalay, Y.E. (2006). The impact of information technology on design methods, products and practices. Design Studies 27(3), 357380. 
Kolarevic, B. (2001). Digital fabrication: Manufacturing architecture in the information age. In proceedings of the Association for Computer Aided Design in Architecture (ACADIA): Reinventing the discourse. Buffalo, New York. Gallagher Printing, Inc. 268-277.

Kolarevic, B. (ed). (2003). Architecture in the Digital Age: design and manufacturing. New York: Spon Press.

Larsen, K.E., Schindler, C., Scheurer, F., \& Stori, S. (2008). The ringve botanical garden viewing platform. In Proceedings of the 26th eCAADe Conference. Antwerpen, Belgium, 783-790.

Lim, C.K. (2003). Is a pen-based system just another pen or more than a pen? Master thesis, Graduate Institute of Architecture, National Chiao Tung University, Taiwan.

Lim, C.K. (2006). From concept to realization. In Proceedings of the Conference of the Association for Computer Aided Design in Architecture (ACADIA). Louisville, Kentucky, 386-391.

Lim, C.K. (2009). Digital CAD/CAM media realize Chinese Calligraphic aesthetics in architectural design. In Proceedings of Computer Aided Architectural Design in Asia (CAADRIA 2009), Yunlin, Taiwan. 225-234.

Liu, Y.T. (1996). Understanding of architecture in the computer era. Taipei: Hu's.

Liu, Y.T., \& Lim, C.K. (2006). New Tectonics: A preliminary framework involving classic and digital thinking. Design Studies 27, 267-307.

Liu, Y.T., \& Lim, C.K. (2009). New Tectonics: Towards a new theory of digital architecture: 7th Feidad Award. Basel, Switzerland: Birkhauser.

Lynn, G., \& Rashid, H. (2002). Greg Lynn and Hani Rashid architectural laboratories. Rotterdam: NAi Publishers.

Mark, E. (2008). Animated parametric rapid prototyping. In the Proceedings of the 26th eCAADe Conference, Antwerpen, Belgium. 897-904.

Million, H. A. (1994). The Renaissance from Brunelleschi to Michaelangelo. New York: Rizzoli.

Mitchell, W. J., \& McCullough, M. (1991). Digital design media: A handbook for architects and design professionals. New York: Van Nostrand Reinhold.

Ni, S.C. (2009). Development and experiment for the curriculum of fundamental digital design. PhD. thesis, Department of Civil Engineering, Tam Kang University. Taiwan.

Sass, L. (2006). Materializing design: The implications of rapid prototyping in digital design. Design Studies 27(3), $325-355$.

Schoch, O. (2006). Teaching digital design and fabrication @ ETH Zurich, in Chiu, ML (ed) Re-imaging Architectural Design Studios, ARCHIDATA. 172-183.

Schodek, D., Bechthold, M., Griggs, K., Kao, K. M., \& Stenberg, M. (2005). Digital design and manufacturing: CAD/CAM applications in architecture and design. Hoboken: John Wiley \& Sons.

Schön, D. A., \& Wiggins, G. (1992). Kinds of seeing and their function in designing. Design Studies 13, 35-156.

Shih, N.J. (1996). A Study of Computer-aided Basic Design in Architecture. Journal of Design 1(1), 67-84.

Smith, A. C. (2004). Architectural model as machine: A new view of models from antiquity to the present day. Oxford: Architectural Press.

Wang, J.C. (2003). BAUHAUS: The root of modern design education. Taipei: Yi Feng Tang.

Zevi, B. (1981). The modern language of architecture. Van Nostrand Reinhold. 